\title{
Understanding Nature's Way of Regulating Stress will Improve Animal Welfare and Productivity
}

\author{
Tilbrook AJ* \\ Centre for Animal Science, The University of Queensland, Australia
}

Submission: December 16, 2018; Published: January 18, 2019

*Corresponding author: Tilbrook AJ, Centre for Animal Science, Queensland Alliance for Agriculture \& Food Innovation, The University of Queensland, Australia

\begin{abstract}
Understanding the mechanisms by which the body suppresses stress responses, as commonly occurs during lactation in a range of species, would provide the means to develop treatments and strategies to reduce stress in animals, especially farm animals. This would result in improvements in welfare and productivity by eliminating the detrimental impacts of stress. There has been substantial research to demonstrate that frontline stress responses are reduced during lactation, to highlight the importance of the salience of the stressor in these responses, and to identify many of the fundamental mechanisms and regions of the brain involved. Nevertheless, the extension of this knowledge to develop the means to reduce stress in the field are lacking and are required. Translation of this knowledge will lead to important benefits in terms of improved welfare and productivity in farm animals.
\end{abstract}

Keywords: Stress; Stress response; Lactation; Welfare; Production; Reproduction

\section{Introduction}

I propose that treatments and strategies to overcome the detrimental effects of stress on welfare and productivity could be developed if we understood the mechanisms by which stress responses are attenuated during the natural process of lactation. Clearly, the most effective mechanisms to suppress stress responses will undoubtedly be those that the body itself uses [1], such as occurs during lactation. Targeted research is required to fully understand these mechanisms, but that should not be difficult. It simply needs to be done. It would be a worthy research pursuit because the benefits would be realised through improved animal welfare and production.

Normal stress responses are critical to a healthy life but there are times when stress can have a negative impact on the welfare and productivity of farm animals. For example, stress can negatively impact the welfare of animals and inhibit production [2] and reproduction [3]. This is especially the case if the responses to stress are ongoing (chronic), or occur repeatedly, or if they occur at a critical time [4]. It stands to reason, then, that there would be substantial advantages to being able to control the impact of stress on animals, particularly at critical times. Despite a huge research effort over many years, we have surprisingly little wherewithal to achieve this. A solution may well lie at hand, however, in understanding the natural attenuation of stress responses that commonly occurs in females during late pregnancy and lactation.
There are many examples of attenuated stress responses in lactating females in a range of species [1]. The term hyporesponsiveness has been commonly used to describe this phenomenon. We have given the topic considerable attention in sheep and have shown the importance that the presence of the offspring plays, particularly when the offspring suck $[4,5]$. Admittedly, it is not always the case that stress responses are attenuated during lactation. It is influenced by the type of stressor. If there appears to be a threat to the dam or her offspring, such as the presence of a predator to lactating sheep, stress responses occur so that the dam can defend her offspring and herself [3]. Nevertheless, this does not detract from the thesis that applied benefits could be derived from understanding the natural regulation of stress during lactation because this argument is predicated on understanding the mechanisms for when stress responses are attenuated during lactation. As indicated above, this clearly occurs commonly and across species.

There has been research on the mechanisms of regulation of stress responses during lactation, but the knowledge is not at the point where it can be applied in the field to improve welfare and productivity. In other words, there is a critical gap in the knowledge required to develop treatments and strategies that are sustainable and can be applied in the field to improve the welfare and productivity of farm animals. Most of the research 
has focused on the fundamental neuroendocrine regulation of frontline stress responses including identification of key brain regions [6]. This research has been important, and it undoubtedly lays the foundation for the work that is required to achieve applied outcomes. The next steps are to translate this knowledge so that it can be applied to improve the welfare and productivity of farm animals.

It is worth noting that this opinion piece is not concerned with the biological or evolutionary reasons for the manner in which stress responses are influenced during lactation. Rather, it is simply drawing attention to a natural phenomenon were, under certain conditions, there is attenuation of stress responses. If we understood this well, to the point where the information could be translated to the field, we could improve the welfare and productivity of farm animals.

\section{Conclusion}

The welfare and productivity of farm animals could be improved by applying treatments and strategies to reduce stress at critical times. These treatments and strategies could be developed from an improved understanding of natural mechanisms of attenuation of stress responses, such as occurs during lactation.
It is suggested that there needs to be a targeted research effort to achieve this.

\section{References}

1. Tilbrook AJ, Clarke IJ (2006) Neuroendocrine mechanisms of innate states of attenuated responsiveness of the hypothalamo-pituitary adrenal axis to stress. Frontiers in Neuroendocrinology 27(3): 285307.

2. Tilbrook AJ, Ralph CR (2018) Hormones, stress and the welfare of animals. Animal Production Science, 58: 408-415.

3. Ralph CR, Tilbrook AJ (2016) The hypothalamo-pituitary-adrenal (HPA) axis in sheep is attenuated during lactation in response to psychosocial and predator stress. Domestic Animal Endocrinology, 55: 66-73.

4. Ralph CR, Tilbrook AJ (2016) Invited Review: The usefulness of measuring glucocorticoids for assessing animal welfare. Journal of Animal Science, 94(2): 457-470.

5. Tilbrook AJ, Turner AI, Ibbott MD, Clarke IJ (2006) Activation of the hypothalamo-pituitary-adrenal axis by isolation and restraint stress during lactation in ewes: Effect of the presence of the lamb and suckling. Endocrinology, 147(7): 3501-3509.

6. Hillerer KM, Woodside B, Parkinson E, Long H, Verlezza S, et al. (2018) Gating of the neuroendocrine stress responses by stressor salience in early lactating female rats is independent of infralimbic cortex activation and plasticity. Stress, 21(3): 217-228.

Your next submission with Juniper Publishers
will reach you the below assets
- Quality Editorial service
- Swift Peer Review
- Reprints availability
- E-prints Service
- Manuscript Podcast for convenient understanding
- Global attainment for your research
- Manuscript accessibility in different formats
( Pdf, E-pub, Full Text, Audio)
- Unceasing customer service
Track the below URL for one-step submission
https://juniperpublishers.com/online-submission.php

